\title{
Human Genetic Engineering: The Historical Perspective
}

\author{
V.Siddesh Padala ${ }^{\# 1}$, Dr.D.V.Pushpalatha ${ }^{\# 2}$ \\ \#1 Liberty High School, Frisco, TX,siddesh.padala@gmail.com \\ \#2 Frisco, TX, dvplatha@gmail.com
}

\begin{abstract}
Genetic editing or engineering is modern science focused on modifying genes to form hybrid genes, which are more effective and productive organisms. While there has been a breakthrough innovation empowering life's but also brought in severe concerns on the misuse of his technology. This paper dwells through some of them.
\end{abstract}

\section{OVERVIEW}

Over the years, scientists have experimented on interbreeding of genes among many organisms through the process of genetic editing. In the beginning, this technology was used to improve food output by altering plants to aid in stopping starvation for millions of people during the Green Revolution. As the technology developed, prospects of altering human genes became an achievable task, as scientists saw it as a viable asset against hereditary diseases. This led to technological advances, new methods, and inspiring ideas that opened a new door in dealing with genetic diseases. For example, due to this discovery "designed babies have a bright future in the face of science because they are genetically engineered to be: disease-free"[1]. Furthermore, as countries have evolved their understanding of this technology they have started to experiment on the prospect of creating an immortal human. For example, Jiankui of the Southern University of Science and Technology in Shenzhen, China, says "he used human embryos modified with the gene-editing technique CRISPR to create twin girls"[2]. Not only is this a huge step towards immortality but this implication provides evidence on how the world is adapting and breaking free of the ethical issues that surround this issue. This leads to the question; How has the practice of human genetic engineering/cloning affects the people in the U.S 20th and 21st century? Although genetic engineering in the past has been regarded as immoral and has received a negative response, it is a final panel breakthrough in science that paved a path for advancements in science.

\section{HISTORICAL IMPACTS}

Research on this technology has been going on for several decades now and whether "human genetic engineering phenomenon" is the best viable option for curing diseases all around the world has become an important question[3]. For example, in research done called The Human Genome published by the National Health Institute, a National American awardwinning company, it was stated that genetic engineering has progressed and provided positive results in altering human DNA. This further motivates scientists to carry forward in their trials and petition for human and animal trials to test the results. Not only did this lead to the idea of free babies that can be genetically edited to promote better health but also lineage diseases that are received through the family tree. For instance, in a journal published by the National Academy of Sciences, revealed that "treated stem cells demonstrated markedly enhanced VEGF production, cell viability, and engraftment into target tissues"[4]. This is the most advanced process of this technology that has been made towards the process and as scientists all around the world proceed to further improve the dream of a disease-free world may be here sooner than expected. 


\section{POSITIVE IMPACTS}

The hope of improving human life had only been in theory, but now the dream has become a reality. In his article, "Genetic Engineering",Nolberg, a scientist for the National Science Department, defines genetic engineering as the use of technology to manipulate the genetic composition of an organism and mold it accordingly. Through this technology, which has taken the world by storm in its potential, we can make tremendous changes in the medical field. Although in the past this technology was only used for simple tasks, the world of today relies on this "god gift" for one sole purpose of the improvement of health and to become "the healer" of humans. [5]. In 1973, two researchers in California, Stanley Cohen, and Herbert Boyer, spliced recombinant DNA strands into bacteria that produced copies of the foreign DNA" [6]. This is major evidence and an important result that shows the positivity genetic editing can bring to the world. Additionally, as observed in the past, deaths of most civilizations have occurred due to diseases, from lineage or spread of infections. The primary goal of genetic engineering as stated in a Journal published by Encyclopedia of Health is to "Change the world and humanity for the better" and "to prevent the loss of innocent lives that are plagued by diseases"[7]. Although this technology is ethically immoral and many people voice their negative opinion, the improvements and liabilities of gene cloning have become a viable option to reduce the deaths that we couldn't stop in the past. Finally, genetic engineering poses a huge benefit to the world that can lead to a new America and the world.

\section{NEGATIVE IMPACTS}

Even though genetic engineering has provided results never seen before it is widely criticized by bioethicists in the United States. In an article called "The trust game: CRISPR for human germline editing unsettles scientists and society," people argue that "genetic editing poses a huge threat to the society of the U.S" "and "is extremely unfair for the many honest and sincere scholars working to adhere to moral practices in the sciences" [8]. Many scientists reject this technology as the world of today proves to misuse it for other purposes. For example, as stated by John Evans in the article Playing god, technology can be used as weapons in the military. Also, the prospect of a SuperHumans is a possible outcome of this process. Not only will this put America in chaos but also if the technology ends up in the wrong hands the effects may be detrimental and also as stated by many leading experts may also lead to a World War 3[9][10]. Another major negative aspect of this technology is that once the gene is altered it cannot be changed back, this poses a huge risk as many new infections epidemics can be born and could spread throughout America and even the world[11][12]. With everything considered the idea of this technology posing a huge problem for America is a highly possible outcome.

\section{CONCLUSION}

Throughout history, the overall processes and advances made in genetic engineering have been for the sole purpose of making a new and better world for humans. This comes in the form of reducing the deaths of people that occur due to diseases and genetics. Many prospects have been researched on how to make this idea work to help the human populations. The ideas of disease-free and immortal humans have shown progress over the years and are viable soon. However, many think that genetic editing is a huge risk and would lead to many negative impacts that America and the world. The risk comes from the idea of misuse of this technology. This can be prevented through a solution that would help the people of the U.S. It is in the form of creating an organization in the UN that is specially made to monitor the progress of genetic engineering and making sure that it doesn't end up in the hands of wrong people. This and also making this technology applicable to the medical law. This not only allows for the controlled use of this technology but also allows progress at 
a controlled rate. Overall, although the idea of altering genes sounds appealing and has shown major potential, the drawbacks that it carries have to be considered and processed to allow for a better America and the world in the present and the impending future.

\section{REFERENCES}

I. Doudna, Jennifer A., and Emmanuelle Charpentier. "The new frontier of genome engineering with CRISPR-Cas9." Science 346.6213 (2014): 1258096. https://innovativegenomics.org/wp-content/uploads/2016/06/Doudna-CharpentierScience-2014.pdf

II. Stein, Rob. "Chinese Scientist Says He's First To Create Genetically Modified Babies Using CRISPR." NPR, NPR, 26 Nov. 2018, www.npr.org/sections/healthshots/2018/11/26/670752865/chinese-scientist-says-hes-first-to-genetically-editbabies

III. Watts, Christine, Ph. D. ..B.App.Sc. .. B.Sc. "Genetically Modified Organisms." Salem Press Encyclopedia of Science, 2018. EBSCOhost, https://docs.google.com/document/d/1zNG6duLvFB9ucEBPe4SKzHx4kKWsAiJI1_5Q5-PBcQ/edit?usp=sharing

IV. Yang, Fan, et al. "Genetic engineering of human stem cells for enhanced angiogenesis using biodegradable polymeric nanoparticles." Proceedings of the National Academy of Sciences 107.8 (2010): 3317-3322. https://www.pnas.org/content/107/8/3317.short

V. Evans, John H. Playing god?: human genetic engineering and the rationalization of public bioethical debate. University of Chicago Press, 2002. https://books.google.com/books?hl=en\&lr=\&id=Vj2ODMWtFPQC\&oi=fnd\&pg=PR $\underline{5 \& d q}$

human + genetic + engineering \&ots $=a 7 t w v E M w \&$ sig $=u k K h 04 g R 7 e O g 1 \_R 6 C u \_46 q o p$ FWE\#v=onepage \& $q=$ human $\% 20$ genetic\%20engineering $\& f=$ false

VI. Bankston, Carl L. ..III, PhD, and Sean A. Valles. "Socio-Ethics of Genetic Engineering." Salem Press Encyclopedia of Health, 2017. EBSCOhost, https://drive.google.com/open?id=1k12udNiKbewlkXztzFodBctJ M-AEeOh

VII. Laney, Dawn A, etal, "Genetic Engineering." Salem Press Encyclopedia of Science, 2018. https://docs.google.com/document/d/1gxejNConkJrfq8Fs6_5QKXoYK4pZl9jGMQxvel ZVpOg/edit? usp=sharing

VIII. Braun, Matthias, and Darian Meacham. "The trust game: CRISPR for human germline editing unsettles scientists and society." EMBO reports (2019): e47583.

http://embor.embopress.org/content/embor/early/2019/01/02/embr.201847583.full.pdf

IX. Miah, Andy. Genetically modified athletes: Biomedical ethics, gene doping and sport. Routledge, 2004

https://drive.google.com/open?id=11EplS_NZLYwMfI7ZRwCZKIOznlEjULqN

X. Nordberg, Ana, et al. "Cutting edges and weaving threads in the gene editing $(Я)$ evolution: reconciling scientific progress with legal, ethical, and social concerns." Journal of Law and the Biosciences 5.1 (2018): 35-83.

https://drive.google.com/file/d/1VoTdLhowS8mP6Ve3mUSMDMuCWoZHkvG/view? usp=sharing

XI. Gossett, D. R., and Karen N. Kähler. "Biotechnology and Genetic Engineering." Salem Press Encyclopedia, 2018. EBSCOhost, https://drive.google.com/file/d/1J8fXh69h89oJCFQ61U2PT U3s56zPqUK/view? usp =sharing 
DOI : https://dx.doi.org/10.26808/rs.ed.i9v5.02

International Journal of Emerging Trends in Engineering and Development

Issue 9, Vol.5(Aug-Sep 2019)

Available online on http://www.rspublication.com/ijeted/ijeted_index.htm

ISSN 2249-6149

XII. Ayala, Francisco J. "Cloning humans? Biological, ethical, and social considerations." Proceedings of the National Academy of Sciences 112.29 (2015): 8879-8886.

https://www.pnas.org/content/112/29/8879.short 